\title{
FLYWHEEL BATTERIES FOR VEHICLES
}

By:

J.H. Beno

R.C. Thompson

R.E. Hebner

Autonomous Underwater Vehicles Workshop in San Antonio, Texas, June 20-21, 2002

Co-sponsored by IEEE/Oceanic Engineering Society and Southwest Research Institute

$\mathrm{PN}-271$

Center for Electromechanics

The University of Texas at Austin

PRC, Mail Code R7000

Austin, TX 78712

(512) 471-4496 


\title{
Flywheel Batteries for Vehicles
}

\author{
Joseph Beno, Richard Thompson, and Robert Hebner \\ The University of Texas at Austin \\ Austin, TX 78712
}

\begin{abstract}
Energy storage flywheels are useful in power conditioning applications, i.e. when there is a mismatch between the power generated and the power required by the load. Two examples of this mismatch are a temporal mismatch and a mismatch in magnitude. The use of a flywheel in a hybrid vehicle, for example, permits the engine to be designed to provide only the power needed to overcome steadystate losses and not have the inefficiencies that result when the engine must also provide power for maximum acceleration.
\end{abstract}

While power management has provided the opportunities for flywheel batteries in vehicles, advances in technology have made the systems more practical. The key advance is the development of very high strength, long-life composites. These materials have significantly improved the energy density in the system over what could be achieved with a steel wheel by permitting much higher rotational velocities. So, smaller, lighter wheels can store energy in the range from less than a kilowatt-hour to more than 100 kilowatt-hours. Other important advances have been in magnetic bearings that allow reliable high-speed operation and in power electronics to control the output power.

Vehicular operation does produce new issues that were less significant in the more traditional stationary applications. One of the most obvious among these is torque management. In charging or discharging a flywheel, the rotational velocity is changed and a torque is produced. For example, systems intended for the International Space Station, where torque management is critical, the initial plan is to cancel torque by using two counter-rotating flywheels. Once confidence is gained in this mode of operation, energy will be distributed among various flywheels to produce the net torque needed for stable operation. For terrestrial vehicles, the flywheel is in a gimbled compliant mount with the axis of rotation orthogonal to the plane of vehicle motion. This orientation permits torque to be compensated by the magnetic bearings and the mount. Tests show that the mount and bearing system can accommodate the shock and vibrations, as well as traveling up or down grades, expected under on-road operation.

\section{INTRODUCTION}

To optimize the performance of any complex mobile system, and autonomous underwater vehicles are such systems, it is frequently useful to separate various power needs and meet them with sources optimized for the particular application. This is the approach taken, for example, in hybrid cars and buses. The steady load is supplied from an internal combustion engine driving an electric generator. Batteries or flywheels can handle the power needs of acceleration or regenerative braking.

A second, similar example is a satellite in low earth orbit. The sun provides prime power. During the approximately one third of the orbit when the earth is between the satellite and the sun, the satellite can operate from battery or flywheel storage. In addition to routine operation, the satellites occasionally need higher levels of power for such applications as position adjustment, communications, radar, or lasers. Batteries or flywheels can be attractive sources of power for these transient power needs [1].

A flywheel is an electromechanical approach to energy storage. To store electricity, a motor is used to convert the electrical energy from an external source into the rotational energy of a flywheel. Using the motor as a generator and extracting energy retrieves the stored energy and slows the flywheel. A complete flywheel battery system consists of the flywheel, magnetic bearings, a motor/generator, power electronics and control electronics. Flywheel systems with high energy density are made of composite material because of the demands for high strength. The requirement for high strength is fundamental for small flywheels. Specifically, for a cylinder (the typical shape of a flywheel, see figure 1 ) of mass density $\rho$, length $l$, inner and outer diameters $r_{i}$ and $r_{0}$ respectively, rotating with angular velocity $\omega$, the stored mechanical energy is:

$$
\mathrm{E}=l \pi \rho \omega^{2}\left(\mathrm{r}_{\mathrm{o}}{ }^{4}-\mathrm{r}_{\mathrm{i}}^{4}\right) / 4
$$

The energy scales as $\omega^{2}$. So, if flywheels are to be small and light yet store significant energy, they must have a large angular velocity. Generally, the radial $\left(\sigma_{\mathrm{r}}\right)$ and hoop $\left(\sigma_{\theta}\right)$ stresses at a given radius are also both proportional to $\omega^{2}$. Thus, small light flywheels that store 
considerable energy must also operate well at high stress levels. This fundamental fact has driven modern flywheels to incorporate composite materials. Composites can be made to have higher strength per unit mass than metals. Thus, composites, particularly those made from carbon fiber and epoxy, are finding application in flywheels.

\section{Cyclic Testing}

One of the key attributes of energy storage devices is the ability to support a large number of charge-discharge cycles. Tests showing excellent behavior for flywheel batteries have recently been completed. The test procedure was to apply 112,00 cycles to a test flywheel in which the speed is ramped from $2.8 \times 10^{3} \mathrm{rad} / \mathrm{s}$ to $3.8 \times 10^{3} \mathrm{rad} / \mathrm{s}$. For the wheel tested, the maximum rotational velocity corresponds to a tip speed of $825 \mathrm{~m} / \mathrm{s}$. The test temperature was about $60 \mathrm{C}$. This variation is from $75 \%$ to $100 \%$ of full speed and from $64 \%$ of the stored energy to $100 \%$ of the stored energy. This range was selected to minimize test time while testing under the most stringent conditions.

The test article was instrumented and some minor variations were detected during the tests. After 93,500 cycles, mass center shift equivalent to $28 \mathrm{gm}$-mm was detected. The testing was interrupted and the flywheel and drive assembly were inspected. This inspection provided no cause for the indicated shift and testing was continued. After about 101,000 cycles, small surface "tear" in one face of the flywheel was detected because the event caused a mass balance shift equivalent to $114 \mathrm{gm}-\mathrm{mm}$. As this shift was so small, testing was continued without incident to 112,000 cycles, which completed the planned testing. While a single test is obviously not statistically significant, successful operation in excess of 100,000 cycles is consistent with the expectation for very long life for composite flywheels.

\section{EFFECTS OF MOTION}

\section{A. Effects of Torque}

A key factor in the mobile application of flywheel technology is to predict and control the effects of motion, shock, and vibration on the flywheels. The first motion related feature is control of the torque produced as a flywheel is accelerated or decelerated. The basic approach to managing this torque is to arrange two flywheels counter-rotating on the same rotational axis. In this way, the wheels can be controlled to produce no net torque on the vehicle. The more versatile approach is to use a number of flywheels in a vehicle so as to permit the operation of an integrated power and attitude control system. The repartitioning of energy among flywheels is possible because of the high efficiency of a flywheel. Typically, more than $97 \%$ of the electrical energy supplied to the flywheel is stored as mechanical energy. Integrated power and attitude control is an active research area [2].

\section{B. Motion of the Axis of Rotation}

Initial work to define shock and vibration levels has been performed. Shock and vibrations are transmitted between the vehicle and the rotating flywheel through both the flywheel bearings and the mounting of the flywheel to the vehicle. For this work, the flywheel was rotating in vacuum on magnetic bearings. The magnetic bearings are augmented by high-speed mechanical back-up bearings. The results presented here are for tests intended to provide some operating parameters for ranges of external disturbances that can be accommodated by the magnetic bearings alone. Operational conditions that would require the use of the back-up bearings would significantly reduce the life of the system.

In addition, to the bearing system, the flywheel housing was also mounted to attenuate forces on the rotating flywheel. Two attenuation approaches were used. First, the flywheel housing was gimbal-mounted. Second the gimbal frame was shock mounted.

For these tests, the flywheel had a rotational axis in the $z$-direction and rotation was considered around the $x$-axis (roll) and the y-axis (pitch). It is assumed that the flywheel was being transported along the $\mathrm{x}$-axis. The specially constructed test table on which the flywheel system was mounted, was stationary, but was programmed to produce the sequence of angular motions summarized in Table 1 . The angular displacements and the rate of change of those angular displacements were those estimated for a specified land-based application. The tests were performed at 1.5 times the anticipated rate of angular change in an attempt 
to compensate for any uncertainty in the estimated values.

TABLE 1

TABLE 1
TEST SEQUENCE

\begin{tabular}{|c|l|l|}
\hline $\begin{array}{c}\text { Angle } \\
\text { (mrad) }\end{array}$ & $\begin{array}{c}\mid \text { Rate } \mid \\
(\mathrm{mrad} / \mathrm{s})\end{array}$ & $\begin{array}{c}1.5 \mathrm{x} \mid \text { Rate } \mid \\
(\mathrm{mrad} / \mathrm{s})\end{array}$ \\
\hline-4 pitch & 4 & 6 \\
\hline-35 roll & 52 & 78 \\
\hline+35 roll & 70 & 105 \\
\hline+9 pitch & 9 & 14 \\
\hline-35 roll & 35 & 52 \\
\hline+35 pitch & 9 & 14 \\
\hline-35 pitch & 18 & 27 \\
\hline+70 roll & 70 & 105 \\
\hline-70 pitch & 70 & 105 \\
\hline+35 roll & 18 & 27 \\
\hline+9 pitch & 9 & 14 \\
\hline-4 pitch & 4 & 6 \\
\hline-35 roll & 18 & 27 \\
\hline-70 roll & 70 & 52 \\
\hline-4 pitch & 4 & 6 \\
\hline-54 pitch & 108 & 162 \\
\hline+9 pitch & 9 & 14 \\
\hline & & \\
\hline & 9 & \\
\hline
\end{tabular}

In Table 1, the positive and negative indications are arbitrary but given to indicate opposite directions of motion.

The tests were very successful with no touchdown events recorded during the final tests. Rotor motion in the magnetic bearing was typically less than $13 \mathrm{~mm}$ in the radial direction, and up to $18 \mathrm{~mm}$ in the axial direction. Clearances in both the radial and axial directions (before impacting the backup bearings) are 25 $\mathrm{mm}$, leading to the conclusion that bearing control was stable and touchdown events will be infrequent at these angles and rates. For full three-dimensional operation, it is likely, but not yet demonstrated, these rates of angular change are acceptable even with larger angular changes.

\section{Motion along the Axis of Rotation}

A second series of tests were shock tests of the system. Using the same testing platform as used above, the shocks were administered along the axis of rotation, i.e. in the z-direction. Peak acceleration loading during this testing was nearly $30 \mathrm{~m} / \mathrm{s}^{2}$ for about $0.1 \mathrm{~s}$. Because of the vibration isolation, the flywheel experienced approximately half of the applied acceleration. When the acceleration was about $20 \mathrm{~m} / \mathrm{s}^{2}$, the magnetic bearings were able to safely manage the transmitted shock without impacting the backup bearings. At $30 \mathrm{~m} / \mathrm{s}^{2}$, however, there was some contact with the back-up bearings but no apparent damage to the system. These results suggest that long-term operation in the presence of axial shock requires a mounting system that reduces the shock to about $10 \mathrm{~m} / \mathrm{s}^{2}$ while the flywheel is spinning. Alternatively, additional work is required to stiffen the magnetic bearings.

\section{CONCLUSIONS}

To provide low weight and small size, flywheels are being constructed of composites composed of carbon fibers and epoxy. These flywheels are spun on magnetic bearings in a vacuum. Two key considerations for these newer systems are service life and the range of forces that can be accommodated by magnetic bearings.

Because there is no life data on composite flywheels under conditions of typical use, a longterm test was conducted. This test showed that the flywheel tested operated for more than 100,000 charge cycles with no degradation in its storage ability. The tests also suggested that fatigue of the carbon fibers or the epoxy might be an important contributor to limiting ultimate life.

Finally, this work showed experimentally that there is a range of operation in which effects of motion can be managed easily. The first consideration was that a resultant torque on the containment system accompanies any change in rotational velocity of the flywheel. Other work is demonstrating this torque can be cancelled or can be used for vehicle attitude control if desired. This work showed that for a specific bearing system, motion of and along the axis of rotation could be accommodated. Although not explicitly demonstrated, these results suggest that magnetic bearing systems are possible for much larger ranges of angular motion if the rate of change is controlled.

\section{REFERENCES}

[1] E. Meintanis, R. D. Bengston, R. E. Hebner, "Power Systems Study for Two Variable Specific Impulse Magnetoplasma Rocket Applications," SPACE 2002, Albuquerque, NM, pp. 22-29, 2002.

[2] T. Giles, "Honeywell's FACETS Ground Test Program Phase II," Aerospace Flywheel Workshop, March 2002, in press. 